Klaus DEINET, Die mimetische Revolution oder die französische Linke und die Re-Inszenierung der Französischen Revolution im neunzehnten Jahrhundert (1830-1871)

(Beihefte der Francia, herausgegeben vom Deutschen Historischen Institut Paris, vol. 50), Stuttgart, Jan Thorbecke Verlag, 2001, 488 p.

Marita Gilli

\title{
OpenEdition
}

Édition électronique

URL : https://journals.openedition.org/ahrf/1273

DOI : 10.4000/ahrf.1273

ISSN : 1952-403X

Éditeur :

Armand Colin, Société des études robespierristes

Édition imprimée

Date de publication : 1 septembre 2002

Pagination : 226-228

ISSN : 0003-4436

Référence électronique

Marita Gilli, « Klaus DEINET, Die mimetische Revolution oder die französische Linke und die ReInszenierung der Französischen Revolution im neunzehnten Jahrhundert (1830-1871) », Annales historiques de la Révolution française [En ligne], 329 | juillet-septembre 2002, mis en ligne le 27 mars 2008, consulté le 24 avril 2022. URL : http://journals.openedition.org/ahrf/1273 ; DOI : https://doi.org/ 10.4000/ahrf.1273

Ce document a été généré automatiquement le 24 avril 2022.

Tous droits réservés 


\section{Klaus DEINET, Die mimetische Revolution oder die französische Linke und die Re-Inszenierung der Französischen Revolution im neunzehnten Jahrhundert (1830-1871)}

(Beihefte der Francia, herausgegeben vom Deutschen Historischen Institut Paris, vol. 50), Stuttgart, Jan Thorbecke Verlag, 2001, 488 p.

\section{Marita Gilli}

Comme son titre l'indique, cette thèse a pour objet d'étudier l'héritage de la Révolution française dans la gauche française du XIX ${ }^{\mathrm{e}}$ siècle. Or, il est incontestable que ses modèles ont non seulement contribué au progrès, mais qu'ils ont changé le regard des républicains français sur les réalités de leur époque. Pour cela, l'auteur n'interroge pas seulement les débats des intellectuels dans la presse ou les brochures, mais les périodes clés du XIX ${ }^{\mathrm{e}}$ siècle français, à savoir les révolutions de 1830 et de 1848 et la Commune de Paris pour voir comment le présent se ressource à la représentation idéalisée du passé dans la conscience des nouveaux acteurs.

2 Le point de départ de l'auteur est l'analyse de la thèse développée par Emile Montégut dans Coup d'œil rétrospectif jeté sur la Révolution française après les événements de 1870-1871, à savoir que « la banqueroute de la Révolution française est désormais un fait accompli, irrévocable ». Pour la première fois, un tel rejet était exprimé de façon aussi catégorique. Pour la thèse de l'auteur, les raisons alléguées par Montégut sont particulièrement intéressantes parce que le malheur ne réside pas tant pour lui dans. l'influence de la Révolution sur l'évolution matérielle de la société (encore que celle-ci ait été désastreuse), mais sur la mentalité des masses, dans la mesure où elle a éveillé de faux espoirs, jouant le rôle d'un "mirage magique ». Montégut développe la thèse déjà émise avant lui que la Révolution française a joué le rôle d'une religion de rechange, ce qui ne pouvait avoir que des conséquences catastrophiques. Pour lui, il y a 
en fait deux révolutions françaises, l'une est un fait historique, l'autre existe en représentation dans les mentalités et n'a fait que croître avec les espoirs déçus. Deinet se propose de montrer que la force de cette représentation a conduit ses adeptes à d'immenses efforts, mais aussi à d'éclatantes erreurs d'interprétation qui ont déterminé le cours et le résultat des trois grandes convulsions selon lui anachroniques du XIXe siècle, à savoir les révolutions de 1830 et de 1848 et la Commune de Paris. Pour ce faire, il utilise le concept de mimesis plutôt que de mythe, concept qu'il utilise au sens aristotélicien du terme, insistant sur l'aspect de $1^{\prime}$ " agir comme si » qui caractérise par ailleurs la plupart des peuples. Ce qui marque l'époque postérieure à la Révolution française, est que cet "agir comme si » quitte la sphère religieuse pour entrer dans celle de l'histoire. Dans la période envisagée qui est celle du siècle insurrectionnel et romantique, les acteurs des révolutions ont imité la Révolution française sans l'avoir vécue, de la même façon qu'un acteur de théâtre joue un rôle. Il ne s'agit donc pas seulement d'une présence du passé dans le présent, mais d'une action de remise en scène lors de laquelle modèle et imitation se confondent. Le problème fondamental de la gauche française a été de savoir dans quelle mesure elle devait s'orienter d'après la Révolution française pour en quelque sorte la terminer et tous les autres problèmes ont toujours été subordonnés à celui-là. Ce qui distingue la thèse de Deinet d'autres études purement intellectuelles, c'est qu'il ne se limite pas à ce qui a été discuté, mais traite aussi ce qui a été mis pratiquement à l'épreuve. Il ne veut donc pas faire une historiographie, ni une représentation diachronique de la gauche française, ni même un examen de l'histoire des mentalités des couches inférieures, mais une analyse de la relation entre théorie et pratique chez une série de révolutionnaires pendant deux générations. Ses sources sont donc les mémoires, les lettres, les journaux et revues de cette époque et, bien sûr, tout le travail qui a déjà été fait par les historiens sur cette période, bien que ces travaux aient généralement sousestimé la problématique de la mimesis. Deinet rend hommage à François Furet d'avoir redécouvert ce thème dans La Révolution de Turgot à Jules Ferry. Depuis, il a été repris par Alice Gérard, Christine Aubry, Stéphane Riais et dans de nombreux travaux occasionnés par le bicentenaire de la Révolution française. Il reste néanmoins mineur chez les historiens français et a été surtout traité par des historiens étrangers ou des historiens de la littérature. Pour son propos, Deinet traite successivement de la Révolution imaginée dans les histoires de Thiers et Mignet, de la révolution de Juillet 1830 entre les modèles de 1688, 1789 et 1793, de la légende de Robespierre, de la première mimesis de 1832 à 1839 avec la fin du mouvement radical, de la gauche française entre réforme et utopie entre 1840 et 1847 , de la révolution narcissique de 1848, de Proudhon et Delescluze à la fin de la Deuxième République, du révisionnisme et de la nouvelle mimesis avec Proudhon, Michelet, Quinet et Tridon, de la gauche française dans le Second Empire, enfin de la Commune de Paris en tant que troisième mimesis.

3 Deinet se demande alors quand a été terminée cette révolution mimétique. Il évoque François Furet qui, s'appuyant sur Halévy, la fait terminer aux élections de 1877, vu que la victoire du parti républicain lui fait perdre son caractère insurrectionnel. Cette position lui semble plausible si l'on s'en tient au domaine politique. Du mythe des perdants, elle serait devenue le chant des gagnants qui n'en auraient plus eu besoin. Deinet en doute et estime que le souvenir de la Grande Révolution perdure, en particulier lors du conflit avec l'ennemi héréditaire allemand. Peut-on envisager qu'elle a duré jusqu'en 1989 et que l'effondrement des pays socialistes lui aurait porté le coup final ? Ce n'est pas non plus l'avis de Deinet qui estime que, si l'on s'en tient au concept 
de mimesis au sens aristotélicien du terme, elle a cessé avec la Commune de Paris, car ensuite, il n'y a plus eu dans l'histoire de la France d'insurrection de gauche. En revanche, il estime qu'avec Albert Mathiez a commencé la seconde mimesis de la Révolution, à savoir la mimesis scientifique.

Il présente la mimesis de la Révolution française comme une forme particulière de la mémoire collective qui a relié d'énormes énergies et a réagi à son tour dans l'histoire. Elle est sans doute, dans l'Europe des deux derniers siècles, la forme la plus active d'interaction entre la mémoire et l'action, la pratique politique et le souvenir. Elle a occasionné des points culminants dans le processus révolutionnaire en France qui sont devenus des points d'ancrages dans l'histoire révolutionnaire de l'ensemble de l'Europe et qui ont fait de la France et surtout de Paris le paradigme de l'évolution de l'histoire. L'observateur objectif ne peut se cacher que cette évolution présente des aspects pathologiques dans la mesure où elle a absorbé des énergies qui se sont épuisées dans un culte stérile du passé et qui ont été perdues pour des réformes raisonnables. L'histoire d'après la Révolution est presque aussi violente et dramatique que la Révolution elle-même et Deinet se montre d'accord avec la vision conservatrice qui, dès avant 1870, voit dans la France la victime d'un sacrifice qui lui a fait revivre la période 1789-1815. Mais il n'en reste pas là, car une telle vision mène à considérer l'histoire comme immuable et soumise à la fatalité. Son analyse a montré au contraire l'aspect peu contraignant du cycle des révolutions au $\mathrm{XIX}^{\mathrm{e}}$ siècle qui ressemble plus aux mouvements d'un pendule de part et d'autre d'un milieu difficile à déterminer. Elle a été un phénomène exceptionnel aux points extrêmes du mouvement du pendule et est restée latente, voire a presque disparu, entre eux. Ce mouvement n'a pris fin que dans la deuxième moitié $\mathrm{du} \mathrm{XX}$ siècle. Deinet considère cette mimesis comme un symptôme de l'ébranlement suscité par la Révolution française et les révolutions qui ont suivi et, dans la violence avec laquelle elle remettait en scène le passé, un miroir des parties du passé qui devaient perdurer dans la mémoire collective ou en être chassés. À la mimesis glorifiante d'une minorité de gauche a correspondu une mimesis de rejet d'une majorité conservatrice qui ne s'est calmée que quand la première a disparu. Avec cette analyse, Deinet se montre donc tout à fait favorable à la thèse qui considère que la Révolution est terminée. 